\title{
Deaf Adolescent Students Knowledge on Transmission and Prevention of HIV/ AIDS: Bechem and Ashanti Schools for the Deaf as a Case Study
}

\author{
Juliana Darlebnim Dinko \\ Special Education Unit, St. Joseph's College of Education, P. O. Box 15 Bechem, Ghana \\ Amos Asamari Alale $(\mathrm{PhD})^{*}$ \\ Guidance and Counselling Unit, University for Development Studies, P O Box1350 Tamale, Ghana
}

\begin{abstract}
The study examined deaf adolescent students knowledge on transmission and prevention of HIV AIDS in Bechem and Ashanti Schools for the Deaf in the Ahafo and Ashanti Regions of Ghana. The study employed a descriptive design. The total population of Junior High School 2 and 3 made up of 147 (male 82 and female 65) was used. HIV/AIDS Knowledge Questionnaires (HAKQ) was the instrument used to collect data for the study. The questionnaires were analyzed using tables, frequencies and percentages. Two research hypotheses were tested using t-test with an alpha level of 0.05 . Results from the questionnaire revealed that majority of students had good knowledge on vaginal/seminal fluid, sex without condom, transfusion with infected blood and sharing sharp/piercing objects as modes of transmitting HIV/AIDS. On the contrary, majority of the students had misconception on mosquito bites, witches and breastfeeding as modes of transmission of HIV/AIDS. Regarding the hypotheses, the study concluded that there is no statistical significant difference between male and female adolescents' knowledge on transmission and prevention of HIV/AIDS. The study recommended that school authorities, Ghana Education Service and Ghana AIDS Commission should collaborate to provide comprehensive education to expose deaf adolescent students to different modes of transmission and prevention. This will dispel the misconception that mosquitoes and witches can transmit HIV/AIDS. Also proper education will help students understand the fact that the virus can be transmitted by breastfeeding.
\end{abstract}

Keywords: Adolescents, Deaf students, HIV/ AIDs, Bechem, Ashanti

DOI: $10.7176 / \mathrm{JEP} / 10-35-02$

Publication date: December $31^{\text {st }} 2019$

\section{Introduction}

Knowledge of Human Immunodeficiency Virus and Acquired Immune Deficiency Syndrome (HIV/AIDS) is important to adolescents who need to be adequately informed about issues concerning the deadly epidemic. The Joint United Nations Programme on HIV/AIDS (UNAIDS) (2011) has described HIV/AIDS as the most infectious and dangerous epidemic in the world's history. The reason for such description could be due to the infectious nature of HIV and also because AIDS has no medical cure yet. UNAIDS (2017) report on global HIV statistics revealed that since the start of the HIV/AIDS epidemic, 76.1 million people have become infected with the virus that causes AIDS, and that 35 million people have died from AIDS-related illnesses. The report further indicated that in 2016, 36.7 million people were living with HIV globally. Of these, 1.8 million people became newly infected with the AIDS virus and 1 million people died from AIDS-related illnesses. In another scenario, United Nations Children Education Fund (UNICEF) report (2017) indicates that adolescents account for about 6 per cent of global HIV infections and about 15 per cent of adult infections. The report concluded that AIDS-related deaths among adolescents have increased over the past decade while decreasing among all other age groups. The WHO (2010), cited in Othman (2014) reported that 50\% of all new HIV infections occur among adolescents aged 15-24 years, they lack knowledge about HIV.

Ghana AIDS Commission, (2017) has stated that all the regions of the country have been affected by the disease since the detection of the first AIDS case in 1986. Adding that, the national HIV/AIDS prevalence continues to rise. This means that everybody including deaf adolescents are at risk of HIV infection in the country.

Regarding deaf people, Mprah (2011) states that they encounter difficulties when accessing information from formal sources such as health professionals and media. For this reason, they often turn to rely on informal sources such as friends and family members for information. This may have dire consequences when it comes to learning about sexual and reproductive health (SRH) issues particularly HIV/AIDS. HIV/AIDS information from peers and family who are not well informed about HIV/AIDS issues may be inaccurate and misleading. It is an undeniable fact that deaf adolescent students are sexually active and may engage in sexual intercourse. Issaka (2015) establishes that adolescent students who are deaf involve in unprotected sex even with other people beside their sexual partners. Such high risk sexual conduct exposes adolescents who are deaf to HIV/AIDS infections.

Once there is no vaccine or cure for HIV/AIDS, adequate and relevant knowledge about HIV/AIDS 
transmission and infection are essential prerequisites for the prevention of HIV infections particularly among adolescents (the deaf inclusive) as they constitute the future generation of all nations. If deaf adolescent students are knowledgeable about how HIV is contracted and how to avoid infections it could lead to a reduction in the infection rate. On the contrary, lack of knowledge about HIV/AIDS could increase the infection rate. One cannot tell whether adolescent students who are deaf in the Bechem and Ashanti school for the deaf have right knowledge of the modes of transmission and prevention of HIV/AIDS. It is against this background that the study sought to investigate the knowledge of adolescent students on HIV/AIDS in the Bechem and Ashanti schools for the deaf. Specifically the study sought to address the following objectives:

1. examine the knowledge of adolescent students who are deaf in Bechem and Ashanti schools for the deaf on modes of transmission of HIV/AIDS.

2. interrogate deaf adolescents in Bechem and Ashanti schools for their knowledge on prevention of HIV/AIDS

3. find out whether differences exist in the knowledge of male and female deaf students regarding the modes of transmission of HIV/AIDS.

4. determine whether differences exist in the knowledge of male and female deaf students on prevention of HIV/AIDS.

\section{Research Questions}

1. What knowledge do deaf adolescent students in Bechem and Ashanti schools for the deaf have about transmission of HIV/AIDS?

2. What is the knowledge of deaf adolescent students in Bechem and Ashanti about HIV/AIDS prevention?

\section{Hypothesis}

1. There is no significant difference between the knowledge of male and female adolescents of Bechem and Ashanti schools for the deaf on transmission of HIV/AIDS.

2. There is no significant difference between the knowledge of male and female adolescents of Bechem and Ashanti schools for the deaf on prevention of HIV/AIDS.

\section{Methodology}

4.1Study Area/Design

The study covered Bechem School for the deaf in the Ahafo Region and Ashanti school for the deaf in the Ashanti Region of Ghana. These two schools are the only special schools for the deaf in their respective regions. Also, the study focused on Junior High School (J.H.S) 2 and Junior High School (J.H.S) 3 students of the 2017/18 academic year. The researchers preferred students from these classes because they had stayed long enough in their respective schools and might have had adequate exposure to the HIV/AIDS Alert school programs which is supposed to be implemented in public basic schools in the country as compared to Junior High School (J.H.S) 1 who are new entrants and might not have gained enough information or exposure on HIV/AIDS Alert school programs, hence their exclusion.

Regarding a research design, the descriptive survey was used for the study. A descriptive survey is a research method that is non-experimental and deals with the relation among non-manipulated variables. Since events or conditions related to deaf adolescent student knowledge of HIV/AIDS do exist or already have occurred, the researcher will gather data for analysis in order to draw meaningful conclusions. The descriptive survey was considered appropriate because it enabled the researchers used questionnaires to obtain opinion from respondents about the transmission and prevention of HIV/AIDS in their respective schools.

\subsection{Population and Sample Size}

The total population for the Junior High 2 and 3 of the two schools was 147. Since the population was not too large, the researchers did not sample instead the entire population (147) was used for the study. The breakdown of the population by school and sex is presented in Table 1 .

Table 1: Population and Sample Size

\begin{tabular}{lccc}
\hline & Males & Females & Total \\
\hline Bechem School for the Deaf & 30 & 19 & $\mathbf{4 9}$ \\
Ashanti School for the Deaf & 52 & 46 & $\mathbf{9 8}$ \\
Total & $\mathbf{8 2}$ & $\mathbf{6 5}$ & $\mathbf{1 4 7}$ \\
\hline
\end{tabular}

4.3 Research Instruments

HIV/AIDS Knowledge Questions (HAKQ) was used to collect data for the study. The HAKQ covered knowledge on transmission and prevention of HIV/AIDS. The questionnaire were closed ended five (5) point Likert scale such as strongly disagree (1), disagree (2), not sure (3), agree (4) and strongly agree (5). The researchers preferred 
the five Likert point questionnaire because some respondents may not know or might not be sure and want to remain neutral. In each of the schools, respondents were put together in one class. The researchers explained the purpose of the study to them in sign language. The questionnaires were given to the students to read through individually. They pointed out terminologies that they did not understand. The researchers explained these terms to them using sign language. Respondents were then given ample time to answer the questionnaire individually.

As part of validating the questionnaires, two experts in the field of Special Education and Measurement and Evaluation were consulted. They examined, scrutinized and made suggestions which were incorporated into the questionnaire to ensure their suitability in measuring the attributes being assessed. Stanger (2004) remarked that content validity is the most powerful technique available to the researcher and through which questionnaires can be validated. Also, internal consistency test was run on the HIV/AIDS Knowledge Questions (HAKQ) by means of Cronbach's Alpha. The Cronbach's Alphas for the questionnaire was $\alpha=0.722$. According to Battaglia (2011), a reliability value of 0.70 and above is reliable and acceptable hence the researchers proceeded with the study.

\subsection{Method of Data Analysis}

The items of the questionnaire was coded and fed into the SPSS version 20 software package and analysed. The analysed data was organised into frequency counts and converted into percentages. The results were presented in tables. Regarding the hypothesis a t-test was used in testing the two hypotheses with an alpha level of 0.05 significance. The "t" test was considered appropriate for testing the hypotheses because the research involves testing the differences of means between two groups; males and females. Again, the data involved was continuous in nature and had met the parametric assumptions (The data is an interval scale and is also normally distributed).

\section{Analysis of Results}

5.1Bio-data of Respondents

Table 2: Sex of Respondents

\begin{tabular}{lll}
\hline Sex & Frequency & Percentage \\
\hline Male & 87 & $\mathbf{5 9}$ \\
Female & 60 & $\mathbf{4 1}$ \\
Total & $\mathbf{1 4 7}$ & $\mathbf{1 0 0}$ \\
\hline
\end{tabular}

From Table 2, it is evident that male respondents (87) represented 59\% whereas their female counterparts $(60)$ represented $41 \%$ of the study population. The male out-numbered the females because more male students might have been admitted into the Bechem and Ashanti Schools for Deaf. However, the differences in number of males over females do not negatively affect the results of the study since both male and female students have common characteristics and require the same information about HIV/AIDS. Corroborating this assertion, UNICEF (2017) report indicates that deaths among adolescents have increased over the past decade while decreasing among all other age groups. This means both male and female adolescents need relevant information in other to minimize the infection rates and consequently reduce HIV/AIDS related death.

Research Question 1: What knowledge do deaf Adolescents in Bechem and Ashanti schools for the deaf have about transmission of HIV/AIDS? List of statements were provided. Respondents were required to indicate their opinion as to whether a particular statement could transmit HIV/AIDS or not. The five-Likert scale was reclassified into a three-point Likert scale. Thus strongly agree and agree were merged as "agree" while strong disagree and disagree merged together as "disagree" Not sure stood alone. The results are presented in Table 3 . Table 3: Adolescent Students Knowledge on Transmission of HIV/AIDS in Bechem and Ashanti Schools for Deaf

\begin{tabular}{|c|c|c|c|}
\hline Mode of Transmission of HIV/AIDS & $\begin{array}{l}\text { Agree } \\
\text { Freq. (\%) }\end{array}$ & $\begin{array}{l}\text { Disagree } \\
\text { Freq. (\%) }\end{array}$ & $\begin{array}{l}\text { Not Sure } \\
\text { Freq. }(\%)\end{array}$ \\
\hline Vaginal/seminal fluid & $107 \quad(72.8)$ & $(27.2)$ & $-\quad-$ \\
\hline Sex without condom & $(70.1)$ & $(25.9)$ & $6(4.1)$ \\
\hline Transfusion with infected blood & $100 \quad(68.0)$ & 27.2) & $7 \quad(4.8)$ \\
\hline Sharing of sharps objects & $(65.9)$ & $(29.2)$ & $8(5.4)$ \\
\hline Mosquito bites & $(66.6)$ & $(19.7)$ & $20(13.6)$ \\
\hline Witches & $(59.1)$ & $(40.9)$ & $-\quad-$ \\
\hline Breast feeding & $(40.1)$ & $(53.0)$ & $10(6.8)$ \\
\hline
\end{tabular}

Table 3 reveals that majority of the students (107: 72.8\%) agreed that HIV/AIDS could be transmitted through vaginal/seminal fluid while $40(27.2 \%)$ disagreed to that statement. Similarly, majority of the students $(103: 70.1 \%)$ opined that sex without condom increase the risk of contracting HIV/AIDS. On the contrary, $38(25.9 \%)$ students disagreed whereas 6 students $(4.1 \%)$ were not sure. Regarding transfusion with infected blood as a mode of transmission 100 students (68.0\%) agreed while 40 (27.2\%) of the students disagreed. Seven (7) students (4.8\%) were not sure. Also, majority (97: 65.9\%) of the students were of the opinion that sharing sharp objects with infected blood transmit HIV/AIDS as compared to 43 (29.2\%) who disagreed. Only 8 (5.4) could not indicate their opinion. 
With references to witches as mode of transmitting HIV/AIDS, 87 (59.1\%) students agreed while 60 (40.9\%) of the students disagreed. On the part of breast feeding, majority of the students $(78: 53.0 \%)$ disagreed to it as mode of transmission as compared to $59(40.1 \%)$ students who agreed. Ten (10) students $(6.8 \%)$ were not sure whether breastfeeding practices could transmit HIV/AIDS or not. It is clear from Table 3 that the majority of the students had correct information or good knowledge on vaginal/seminal fluid, sex without condom, transfusion with infected blood and sharing sharp objects as modes of transmitting HIV/AIDS. On the contrary, majority of the students had wrong information or poor knowledge regarding mosquito bites, witches and breastfeeding as modes of transmission of HIV/AIDS.

Research Question 2: What is the knowledge of adolescents who are deaf have about prevention of HIV/AIDS? In this section, students responded to items regarding HIV/AIDS prevention by indicating whether they agreed, disagreed, or were not sure to statements. The results are presented in Table 4.

Table 4: Adolescent Students Knowledge on Prevention of HIV/AIDS in Bechem and Ashanti Schools for Deaf

\begin{tabular}{llcc} 
& Agree & Disagree & Not Sure \\
Mode of Prevention of HIV/AIDS & Freq. (\%) & Freq. (\%) \\
\hline Avoiding infected blood transfusion & $110(74.8)$ & $37(25.1)$ & - \\
Consistent and correct use of condom & $106(72.1)$ & $32(22.0)$ & $9(6.1)$ \\
Washing genitals after sex & $103(70.0)$ & $33(22.2)$ & $11(7.4)$ \\
Avoiding sharing of sharp objects & $101(68.7)$ & $37(25.1)$ & $9(6.1)$ \\
Avoiding vagina delivery & $82(55.7)$ & $39(26.5)$ & $26(17.6)$ \\
Avoidance from anal sex & $48(32.6)$ & $92(62.5)$ & $7(4.7)$
\end{tabular}

Table 4 shows that majority of the students $(110: 74.8 \%)$ were of the opinion that avoiding infected blood transfusion is a method of HIV/AIDS prevention as compared to 37 (25.1\%) students who disagreed. On the part of consistent and correct use of condom as a method of preventing HIV/AIDS, majority of the students (106: $72.1 \%)$ agreed to it while $32(22.0 \%)$ students disagreed. Nine (9) students representing $6.1 \%$ were not sure. Also, majority of the students (103: 70.0\%) opined that washing of genitals after sex can prevent HIV/AIDS as compared to 33 students $(22.2 \%)$ who disagreed, whereas $11(7.4 \%)$ were not sure. Regarding avoiding sharing of sharp objects, 101 students representing $68.7 \%$ accepted it as method of prevention of HIV/AIDS. On the contrary, $37(25.1 \%)$ students did not agree while $9(6.1 \%)$ were not sure. Also, majority of the students opined that avoiding vagina delivery (Child birth through the vagina) could prevent HIV/AIDS whereas $82(55.7 \%)$ of the students did not agree to this statement. Twenty six students $(26: 17.6 \%)$ were not sure. Finally, majority of the students disagreed that abstinence from anal sex could prevent HIV/AIDS as compared to students who agreed to the statement. Seven (7) students representing (6.4\%) were not sure about the statement. From Table 4, majority of the students had good knowledge or correct information about consistent and correct use of condom, avoiding sharing of sharp objects, avoidance of infected blood transfusion and vagina delivery as methods of prevention of HIV/AIDS. On the other hand, majority of the students had poor knowledge or incorrect information regarding washing of genitals and avoidance of anal sex as methods of preventing HIV/AIDS.

\subsection{Hypothesis Testing}

Hypothesis 1: There is no statistically significant difference between male and female adolescent knowledge on transmission of HIV AIDS in Bechem and Ashanti Schools for the Deaf.

Table 5: Group Statistics and Independent Sample T-test of Male and Female Knowledge of Transmission of HIVIAIDS in Bechem and Ashanti Schools for the Deaf

\begin{tabular}{llllll}
\hline Sex & $\mathrm{N}$ & Means & SD & T-cal. & $D f$ \\
\hline Male & 87 & 24.87 & 5.46 & -.68 & 145 \\
Female & 60 & 25.48 & 5.22 & & \\
\hline
\end{tabular}

At an alpha level of 0.05 , $t$ - critical value is 1.660

Table 5 reveals that the calculated value of t-test is -0.68 . At an alpha level of 0.05 with a degree of freedom of 145 , the critical value is 1.660 . Since the critical value is greater than the calculated value of the t-test, we fail to reject the null hypothesis, which states that there is no statistically significant difference between male and female students knowledge on transmission of HIV/AIDS in Bechem and Ashanti schools for the deaf.

Hypothesis 2: There is no statistically significant difference between male and female adolescents knowledge on prevention of HIVIAIDS in Bechem and Ashanti schools for the deaf 
Table 6: Group Statistics and Independent Sample T-test of Male and Female Students Knowledge of Prevention of HIV/AIDS in Bechem and Ashanti Schools for the Deaf

\begin{tabular}{llllll}
\hline Sex & $\mathrm{N}$ & Means & SD & Cal. t-value & $D f$ \\
\hline Male & 87 & 21.63 & 4.28 & -2.31 & 145 \\
Female & 60 & 23.30 & 4.33 & & \\
\hline
\end{tabular}

At an alpha level of 0.05 , t- critical value is 1.660

Table 6 indicates that the calculated value of t-test is -2.3 . At an alpha level of 0.05 with a degree of freedom of 145 , the critical value is 1.660 . Since the critical value is greater than the calculated value of the t-test, the null hypothesis is accepted. This means there is no statistically significant difference between male and female adolescents knowledge on prevention of HIV/AIDS in Bechem and Ashanti schools for the deaf.

\section{Discussions of Findings}

With regard to students knowledge on mode of transmission of HIV/AIDS, the study revealed students had good knowledge or right information about vaginal/seminal fluid, sex without condom, transfusion of infected blood and sharing sharp objects as modes of transmissions. On the contrary, the students had wrong or poor knowledge of information regarding mosquito bites, witches and breastfeeding as modes of transmissions of HIV/AIDS.

In the first place, vaginal/seminal fluid was one of the modes of transmission of HIV/AIDS that students have good or right knowledge of information. It is in the right direction for the students to be aware that HIV/AIDS could be transmitted through vaginal /seminal fluid. This means student may avoid indiscriminate sex or delay in engaging in sexual intercourse until marriage or use condom during sex. These actions could reduce students' risk of contracting HIV/AIDS among adolescents. This finding is in tandem with other researchers. For instance, Yaw (2011) confirmed in a study that deaf adolescent in special schools in Ashanti region are to a large extend aware that HIV/AIDS can be transmitted by virginal or seminal fluid. Similarly, Issaka (2015) found that deaf adolescent students are strongly aware that sex without condom increases ones risk of contracting HIV/AIDS. However, this finding contradicts that of Andrade and Blaloyi (2010). According to them adolescents who are deaf in South Africa did not have sufficient knowledge about semen and vaginal secretions as modes of transmission of HIV/AIDS. Also, the study revealed that HIV/AIDS can be transmitted through infected blood. It is laudable for deaf adolescent students to be aware that HIV virus can be transmitted through blood. This means they will adopt safer and healthier lifestyles to avoid blood contact with people. For instance they will ensure that they receive blood transfusion only under strict medical and professional setting. This practice could minimize their risk of HIV virus infection. Sharing similar view with this finding, Touko, Mboua, Tohmintain and Perrot (2010) reported that participants who are deaf students considered themselves as potentially at risk of infection through blood transmission.

On the contrary, other findings of the study revealed that students had misinformation or misconception about other modes of transmission. For instance, the study indicated that HIV/AIDS can be transmitted through mosquito bite. This is an indication that students are ignorant about the fact that mosquito bites cannot transmit HIV/AIDS. It is worrisome for deaf adolescent students to think that mosquitoes can transmit HIV/AIDS. By this wrong notion, students may focus attention on avoiding mosquito bites thinking they are protecting themselves against HIV infection, while ignorantly involving themselves in practices that may expose them to the virus. This finding share a similar view with that of Mprah (2013). According to Mprah most deaf adolescent students in Accra and Tamale in Ghana opined that mosquitoes could transmit the virus that causes AIDS. Similarly, Andrade and Blaloyi (2010) found that deaf adolescent in South Africa have the misconception that HIV/AIDS can be transmitted by mosquito bites. Furthermore, the study revealed that HIV/AIDS cannot be transmitted through breastfeeding. This is another misconception or lack of right information. This means that students are not well informed about breastfeeding as a mode of transmission of HIV/AIDS. Such lack of knowledge may cause adolescent mothers who are deaf to breastfeed their babies or advice their relatives to do same even when they know they are HIV positive. This finding contradicts the findings of Appiah-Agyekum and Suapim (2013) who established that most adolescent students indicated that HIV can be transmitted through sucking the breast milk of an infected mother.

Regarding students knowledge on the prevention of HIV/AIDS, the study revealed deaf adolescent students had correct information or good knowledge of some prevention methods such as consistent and correct use of condom, avoiding sharing of sharp objects, avoidance of infected blood transfusion and vagina delivery. On the contrary, the study revealed that students have poor knowledge or incorrect information (misconception) regarding washing of genitals and abstinence from anal sex as methods of preventing HIV/AIDS.

One of the modes of transmission students had good knowledge of is the correct and consistent use of condom. This suggests that adolescents have good knowledge of preventing HIV/AIDS transmission through condom use. By this knowledge, students are more likely to use condom if they are to engage in any sexual intercourse. The finding is consistent with that of Sangowawa (2009) who posited deaf students in Junior High and Secondary Schools in Ibadan, Oyo State have adequate information regarding condom use as an effective measure to prevent 
the transmission of HIV/AIDS. In a similar vein, Touko, Mboua, Tohmuntain, \& Perrot, (2010) discovered that majority of deaf adolescents have the information that the use of condom is a major mode of preventing HIV/AIDS infection. Secondly, the study revealed that students are aware that HIV/AIDS infection may be prevented by avoiding sharing sharp and piercing objects. This is an indication that students have right information about another method of prevention. The implication is that students may be careful not to share sharp/piercing objects such as razors, shaving sticks, and nail cutters, among others. This could reduce their vulnerability of infection with the HIV virus. Corroborating this finding, Issaka (2015) established that most deaf adolescents in selected special schools in Ghana agreed that HIV/AIDS could be transmitted through sharing sharp objects such as needles and blades with infected people.

Contrary to the above good knowledge, the study also revealed that students had poor knowledge or misconception that HIV/AIDS can be prevented through the washing of genital parts after sex. This implies that students are not abreast with all the modes of prevention of HIV/AIDS. This misconception and its action may put them at high risk of contracting the HIV virus as they may indulge in indiscriminate sexual practices. This finding tallies with the findings of other researchers. For example, Andrade and Blaloyi (2010) revealed that deaf adolescent students have the misconception that washing genitals after sexual intercourse and avoiding touching people living with HIV/AIDS could prevent HIV infection. Also, the study indicated that avoiding anal sex cannot reduce a person's risk of getting HIV infection. This is another misconception. It implies that students are not aware that HIV/AIDS can be transmitted through anal sex. The inappropriate knowledge in this regard is worrisome. This is because students may indulge in anal sex thereby exposing themselves to HIV infection. The mucus lining of the anus is very fragile and can easily be bruised; as such, HIV transmission is easier especially if condom is not used. This finding disagrees with Ruma (2009) who found that majority of adolescents opined that avoidance of anal sex could help minimize HIV infections.

With reference to the hypothesis, Hypothesis 1 revealed there is no statistical significant difference in the opinions of male and female students in Bechem and Ashanti Schools for the Deaf of HIV/AIDS transmission. This study is in tandem with Yaw (2011) who found that significant difference do not exist in male and female deaf adolescent knowledge of HIV/AIDS transmission $(\mathrm{t}=1.745, \mathrm{df}=281, \mathrm{p}=.531)$. The similarity in opinion is not surprising because both male and female students are expected to participate in school-based activities about HIV/AIDS. Besides, adequate and relevant information about modes of transmission of HIV/AIDS are essential for both male and female students to conduct themselves appropriately in order not to get infected with the virus. Results from hypothesis 2 showed that there is no statistically significant difference between male and female adolescents' knowledge on prevention of HIV/ AIDS in Bechem and Ashanti Schools for the Deaf. The current finding tallies with the research findings of Mprah (2013) who concluded that male and female deaf students in the cities of Accra and Tamale share similar views in knowledge regarding the prevention of HIV/AIDS. It is logical to expect that both male and female students have similar opinion regarding the prevention of HIV/AIDS. It is so because all students are required to attend HIV/AIDS education and awareness creation programmes, which seek to equip them with basic facts of HIV/AIDS, and appropriate prevention methods to enable them stay uninfected.

\section{Conclusion}

The study concluded that while adolescent deaf students have correct information or good knowledge on vaginal/seminal fluid, sex without condom, transfusion with infected blood and sharing of sharp objects as modes of transmitting HIV/AIDS, they equally have misconception or poor knowledge about mosquito bites, witches and breastfeeding as modes of transmission of HIV/AIDS. This implies that students are not abreast with all the modes of transmission of HIV/ AIDS.

Also, the study established that students are aware that consistent and correct use of condom, avoiding sharing of sharp objects, avoidance of infected blood transfusion and vagina delivery are preventive measures of HIV/AIDS. On the other hand, the study showed students had poor knowledge or incorrect information regarding washing of genitals and abstinence from anal sex as methods of preventing HIV/AIDS. It can be concluded that deaf adolescent have some misinformation about some methods of HIV/AIDS.

Also, the study revealed that there was no statistical significant difference between male and female adolescents' knowledge on transmission and prevention of HIV/AIDS in Bechem and Ashanti Schools for the deaf. This means male and female students show similar opinion in knowledge on both the transmission and prevention of HIV/AIDS. It also means gender is not a significant determinant of students knowledge on HIV/AIDS transmission and prevention respectively.

\section{Recommendations}

1. School authorities, Ghana Education Service and Ghana AIDS Commission should collaborate to provide education and create awareness by exposing students to different modes of transmission. This will dispel the misconception that mosquitoes and witches can transmit HIV/AIDS. Also proper education will help 
students understand the fact that the virus can be transmitted by breastfeeding.

2. Counsellors, School Teachers and Parents should encourage both male and female students to patronise HIV/AIDS seminars as this could help them acquire more relevant and accurate information about the transmission and prevention of HIV/AIDS. This would eradicate the misinformation that washing of genitals could prevent HIV/AIDS. It will also enable students acquire accurate information about the fact that abstinence from anal sex is a method of preventing HIV/AIDS. This could enable them conduct themselves appropriately to minimise or avoid contacting the virus.

\section{References}

Agyemang, S., Buor, D., \& Tagoe-Darko, E. (2012).The extent of knowledge about HIV/AIDS among young people in the Ejura-Sekyedumase district of Ghana.Journal of AIDS and HIV Research, 4(11), 241-247.

Andrade, V., \& Baloyi, B. (2010). HIV/AIDS knowledge among adolescent sign-language usersin South Africa. African Journal of AIDS Research, 9(3), 307-313.

Appiah-Agyekum, N. N., \& Suapim, R. H. (2013). Knowledge and awareness of HIV/AIDS among high school girls in Ghana. HIV/AIDS - Research and Palliative Care, 5, 137-144.

Battaglia, M. P. (2011). Encyclopedia of survey research methods. Thousand Oaks: Sage Publications, Inc.

Ghana AIDS Commission (2015).Country AIDS Response Progress Report- Ghana. Retrievedfromhttp://www.unaids.org/sites/default/files/country/documents/GHA_narrative_report_2015.pdf on $20 / 1 / 2018$

Ghana AIDS Commission (2017) GAC (2017). Ghana records jump in new HIV infections by 70.15\%. Retrieved from https://www.myjoyonline.com/lifestyle/2018/January-13th/ghana-records-80-increase-in-hiv-in-2017report.php on 10/12/2017.

Isaiah, O. O. (2010). Implication of hearing impairment on psychosocial adjustment of secondary school students with hearing loss. Ibadan Journal of Educational Studies, 7, 1-2

Isaiah, O. O., \& Ola, T. A. (2016). Predictors of risky health behaviours among secondary school students with hearing impairment in South -West, Nigeria Faculty of Education, University of Ibadan, Ibadan, Ibadan, Nigeriadoi:10.19044/esj.2016.v12n10p211URL:http://dx.doi.org/10.19044/esj.2016.v12n10p211.

Issaka, A. C. (2015). HIV/AIDS knowledge and sexual behavior among adolescents with hearing impairment in selected special schools for the deaf in Ghana

Mall, S. (2012). HIV prevention issues for deaf and hard of hearing adolescents: Views of parents, teachers, adolescents and organizations serving the Deaf community. Unpublished PhD thesis, Stellenbosch University.

Mprah W.K (2011). Sexual and reproductive health needs assessment with deaf people in Ghana. PhD Thesis, Department of Disability and Human Development, University of Illinois, Chicago, USA.

Mprah, W. K. (2013). Exploring knowledge and attitudes towards HIV/AIDS among deaf people in Ghana. Journal of Disability, 24(2). Retrieved from http://dx.doi.org/10.4102/ajod.v2i1

Mprah, W. K. (2013). Knowledge and use of contraceptive methods amongst deaf people in Ghana. Journal of Disability, 2(1). Retrieved from http://dx.doi.org/10.4102/ajod.v2i1

Ruma, M. M. (2009). Knowledge and awareness of HIV/AIDS among some senior secondary school students in Katsina, Nigeria. Journal of Pure and Applied Sciences, 2(2), 121-126.

Sangowawa , A.O (2009). Sexual practice deaf and hearing secondary school. Journal Home Vol. 7 No.1

Stangor, C. O. (2004). Research methods for behaviourial science. Boston, Houghton Mifflin Co.

Touko, A., Mboua, C. P., Tohmuntain, P., \& Perrot, A. (2010).Sexual risk factors and HIV sero-prevalence among the deaf and hearing-impaired in Yaounde.Sante (Montrouge, France), 20(2), 109-115. DOI:10.1186/17582652-13-5.

UNAIDS (2011).Disability and HIV policy brief.Geneva: UNAIDS.

UNAIDS (2017).Global HIV Statistics Fact: Sheet World AIDS Day 2017.Retrieved from http://www.unaids.org/sites/default/files/media_asset/UNAIDS_FactSheet_en.pdf on 1/10/2017.

UNICEF (2017). Children and AIDS statistical ${ }^{-}$update.Retrieved from https://data.unicef.usaid.gov/pdf_docs/pdacu659.pdf on 09/10/2017.

Yaw, A. (2011). HIV/AIDS Education in regular and special (Deaf) secondary schools in Ghana. Unpublished masters' thesis, University of Jyvaskyla, Finland.

Yousafzai, A. \& Edwards, K. (2014).Double burden: A situation analysis of HIVIAIDS and young people with disabilities in Rwanda and Uganda. London: Save the children 